\title{
The Mechanical and Electrical Effects of MEMS Capacitive Pressure Sensor Based 3C-SiC for Extreme Temperature
}

\author{
N. Marsi, ${ }^{1}$ B. Y. Majlis, ${ }^{1}$ A. A. Hamzah, ${ }^{1}$ and F. Mohd-Yasin ${ }^{2}$ \\ ${ }^{1}$ Institute of Microengineering and Nanoelectronics (IMEN), Universiti Kebangsaan Malaysia, 43600 Bangi, Malaysia \\ ${ }^{2}$ Queensland Micro- and Nanotechnology Centre (QMNC), Griffith University, Brisbane, QLD 4111, Australia \\ Correspondence should be addressed to N. Marsi; norainimarsi@gmail.com
}

Received 18 December 2013; Accepted 29 April 2014; Published 22 May 2014

Academic Editor: Sheng-Rui Jian

Copyright (c) 2014 N. Marsi et al. This is an open access article distributed under the Creative Commons Attribution License, which permits unrestricted use, distribution, and reproduction in any medium, provided the original work is properly cited.

\begin{abstract}
This paper discusses the mechanical and electrical effects on 3C-SiC and Si thin film as a diaphragm for MEMS capacitive pressure sensor operating for extreme temperature which is $1000 \mathrm{~K}$. This work compares the design of a diaphragm based MEMS capacitive pressure sensor employing 3C-SiC and Si thin films. A 3C-SiC diaphragm was bonded with a thickness of $380 \mu \mathrm{m} \mathrm{Si} \mathrm{substrate,} \mathrm{and}$ a cavity gap of $2.2 \mu \mathrm{m}$ is formed between the wafers. The MEMS capacitive pressure sensor designs were simulated using COMSOL ver 4.3 software to compare the diaphragm deflection, capacitive performance analysis, von Mises stress, and total electrical energy performance. Both materials are designed with the same layout dimensional with different thicknesses of the diaphragm which are $1.0 \mu \mathrm{m}, 1.6 \mu \mathrm{m}$, and $2.2 \mu \mathrm{m}$. It is observed that the $3 \mathrm{C}$-SiC thin film is far superior materials to Si thin film mechanically in withstanding higher applied pressures and temperatures. For 3C-SiC and $\mathrm{Si}$, the maximum von Mises stress achieved is $148.32 \mathrm{MPa}$ and $125.48 \mathrm{MPa}$ corresponding to capacitance value which is $1.93 \mathrm{pF}$ and $1.22 \mathrm{pF}$, respectively. In terms of electrical performance, the maximum output capacitance of $1.93 \mathrm{pF}$ is obtained with less total energy of $5.87 \times 10^{-13} \mathrm{~J}$, thus having a $50 \%$ saving as compared to $\mathrm{Si}$.
\end{abstract}

\section{Introduction}

More recent developments in the field of robust micromechanical system (MEMS) for extreme environment such as MEMS pressure sensor have been widely used in airplanes, submarines, gas turbine engine, automobiles, and biomedical devices [1]. MEMS pressure sensor based silicon (Si) materials are not well suited, owing to its desirable and stable material properties under extreme environment due to this limited operating of mechanical and electrical properties that can degrade below temperature of $300^{\circ} \mathrm{C}$ [2]. There are some significant challenges replacing the silicon with silicon carbide (3C-SiC) materials for MEMS application. The 3C$\mathrm{SiC}$ is promising materials that have excellent mechanical and thermal stability for the fabrication MEMS capacitive pressure sensor operating for extreme environment [3]. In improving the performance of MEMS pressure sensor, the use of $3 \mathrm{C}-\mathrm{SiC}$ materials is an alternative offering a new approach to overcome high temperature performance.

The mechanical and electrical properties of 3C-SiC show great promise and effective materials that are highly wear resistant with good mechanical and electrical properties including high temperature strength, chemical stability, and excellent thermal shock resistance applications. In a previous study, Wijesundara and Azevedo have investigated electrical properties of 3C-SiC which is one of the best materials for extending the capabilities of excellent electrical properties such as wide band-gap $(2.3 \mathrm{eV})$, high breakdown field $(1.8 \times$ $\left.10^{17} \mathrm{~cm}^{-3}\right)$, high-saturated drift velocity $\left(2.5 \times 10^{7} \mathrm{cms}^{-1}\right)$, higher thermal conductivity $(5 \mathrm{~W} / \mathrm{cm}-\mathrm{K})$, and electrically robust materials that have been adequately applied in a high temperature, harsh environment, and high power density for MEMS application [4]. The 3C-SiC provides a mechanically superior material compared to $\mathrm{Si}$ that can remain constant 
up to temperature above $500^{\circ} \mathrm{C}$ with relatively high Young's modulus of $450 \mathrm{GPa}$, higher density $\left(3.2 \times 10^{-15} \mathrm{~kg} / \mathrm{\mu m}^{-3}\right)$, and higher yield strength $(21 \mathrm{GPa})$ and Poisson's ration of 0.22 can be operated effectively at extremely high temperature [5].

In this paper, specifically, we focus on the comparison of the movable diaphragm utilizing both materials 3C-SiC and $\mathrm{Si}$ at changes of diaphragm thickness which is $1.0 \mu \mathrm{m}$, $1.6 \mu \mathrm{m}$, and $2.2 \mu \mathrm{m}$ despite having similar layout size when pressures and temperatures are applied to the diaphragms. The MEMS capacitive pressure sensor was designed and simulated using COMSOL Multiphysics software ver. 4.3 via its process simulator tool. The effects of mechanical and electrical of MEMS capacitive pressure sensor is introduced and compared in terms of deflection of the diaphragm, capacitance performance, von Mises stresses distribution into loaded diaphragm and total electric energy in response to applied pressures.

\section{Methodology}

2.1. Modeling of MEMS Capacitive Pressure Sensor Design. In order to design and optimize the dimensional layout of MEMS sensor, both 3C-SiC and Si designs were simulated using COMSOL Multiphysics ver. 4.3 software as shown in Figure 1. The structure was created using $2 \mathrm{D}$ model from cross section of $3 \mathrm{D}$ geometries with functional part for MEMS capacitive pressure sensor, as depicted in Figure 2. A thin diaphragm is held at a fixed potential of 1.0 Volt. The MEMS capacitive pressure sensor consists of 3C-SiC, silicon nitride $(\mathrm{SiN})$, and $\mathrm{Si}$ layers. The structure was initiated by setting $3 \mathrm{C}-\mathrm{SiC}$ as diaphragm, $\mathrm{SiN}$ as an insulator, and $\mathrm{Si}$ as a substrate. The 3C-SiC diaphragm comprises an $\mathrm{Si}$ substrate to form a cavity with the thickness of $2.2 \mu \mathrm{m}$. The height of the cavity is relative to the external pressure suspended over a reference vacuum cavity. The SiN as insulating layer is deposited to avoid the conductor losses from the metal connection between the diaphragm and the substrate.

The diaphragm deflects under an increasing external pressure contacting its substrate. The distance between the diaphragm and substrate exhibits an increase in the MEMS device capacitance value. At a certain pressure, the diaphragm starts to touch the substrate. Due to the change of touched area, the capacitance increases with increasing pressures [6]. Any variation in diaphragm thickness, insulator, and a sealed cavity has a significant impact on the resulting deflection performance that can be manipulated by simulating the MEMS capacitive pressure sensors to perform accurate and reliable output.

\subsection{Simulation Methodology}

2.2.1. Deflection of Diaphragm for $3 \mathrm{C}-\mathrm{SiC}$ and Si. For the purpose of studying the effects of the diaphragm deflection for $3 \mathrm{C}-\mathrm{SiC}$ and $\mathrm{Si}$, COMSOL ver 4.3 software was performed on MEMS capacitive pressure sensor with varying thicknesses which are $1.0 \mu \mathrm{m}, 1.6 \mu \mathrm{m}$, and $2.2 \mu \mathrm{m}$. The gap cavity between the diaphragm and substrate was fixed at $2.2 \mu \mathrm{m}$. The square shaped diaphragm structure with length and width of $2.0 \mathrm{~mm}$

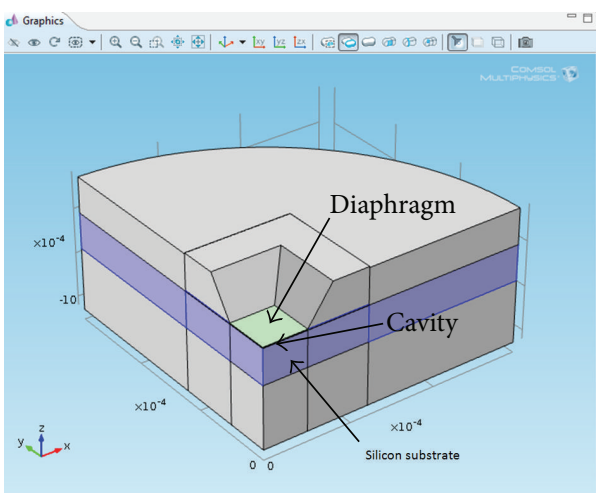

FIGURE 1: Modeling of 3D MEMS capacitive pressure sensor.

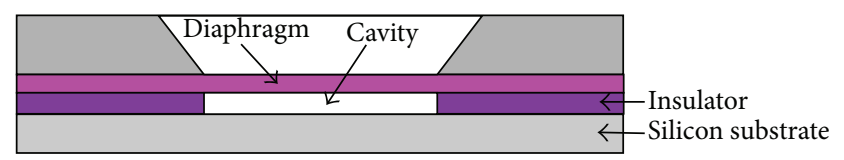

FIgURE 2: Cross section through the MEMS capacitive pressure sensor.

is designed. The performance of diaphragm is analyzed using model builder solver in terms of deflections in response to pressure and temperature changes. The centre deflection of diaphragm $w(x, y)$ for square shape of MEMS capacitive pressure sensor can be defined as [7]

$$
w_{\max }=0.01512\left(1-v^{2}\right) \frac{P L^{4}}{E h^{3}},
$$

where $L$ is the diaphragm length, $h$ is the diaphragm thickness, Young's modulus $E$ and Poisson's ratio, $v$, are subjected to uniform pressure, $P$, and the maximum diaphragm deflection is $w_{\max }$.

2.2.2. Comparison Capacitance for $3 \mathrm{C}-\mathrm{SiC}$ and Si. The basic operation to analyze the capacitance performances of both $3 \mathrm{C}-\mathrm{SiC}$ and $\mathrm{Si}$ materials is using a movable top plate in order to create a variable capacitance. MEMS capacitive pressure sensor is simulated to uniformly distribute the pressure on the surface of the diaphragm. The design of the proposed MEMS pressure sensor diaphragm of width and length was fixed at $2.0 \mathrm{~mm}$ and $2.0 \mathrm{~mm}$, respectively. The capacitance equation can be defined as [8]

$$
C=\frac{\varepsilon_{r} \varepsilon_{0} A}{d},
$$

where $C$ is the capacitance between the two electrodes, $\varepsilon_{r}$ is the permittivity of the dielectric medium used between the two electrodes, $\varepsilon_{0}$ is the permittivity for air $(8.854 \times$ $10^{-14} \mathrm{~F} / \mathrm{cm}$ ), and $d$ is the distance or separation between two electrodes. To analyze the capacitance performance for both materials, the differential thicknesses varying from $1.0 \mu \mathrm{m}$, $1.6 \mu \mathrm{m}$, and $2.2 \mu \mathrm{m}$ and the resulting capacitances between two materials were compared. 


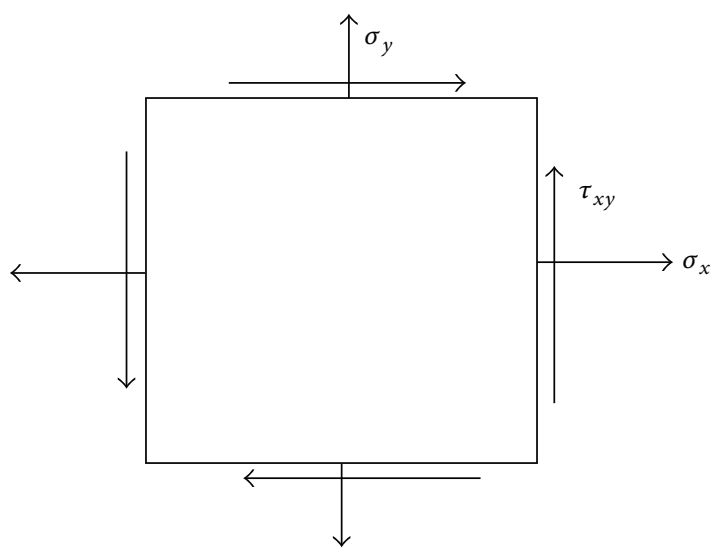

FIGURE 3: 2D stress components.

2.2.3. von Mises Stress. The diaphragm is assumed to be capable of large deformation and once the diaphragm is applied to high increasing pressure loads, the diaphragm will eventually break which generates high levels of stress. The von Mises stresses were obtained after simulation in order to evaluate both $3 \mathrm{C}-\mathrm{SiC}$ and $\mathrm{Si}$ materials performance by its mechanical strength. The maximum von Mises stress criterion is according to Von Mises-Hencky theory, also known as the shear-energy theory or maximum distortion energy theory [9]. Figure 3 shows the 2D state of stress with the independent stress components of $\sigma_{x}$ and $\sigma_{y}$. The third stress component $\sigma_{3}$ can exist on the $z$-axis. In the context of a complicated stress system, the initial step would be to determine the principle stresses $\sigma_{x}, \sigma_{y}$, and $\sigma_{z}$. Three important stress indicators are derived: principle stress, maximum shear stress, and von Mises stress [10].

The principle stresses $\sigma_{1}, \sigma_{2}$, and $\sigma_{3}$ are found to be

$$
\begin{gathered}
\sigma_{1}, \sigma_{2}=\frac{\sigma_{x}+\sigma_{y}}{2} \pm \sqrt{\left(\frac{\sigma_{x}-\sigma_{y}}{2}\right)^{2}+\tau_{x y}^{2}}, \\
\sigma_{3}=0 .
\end{gathered}
$$

The maximum shear stress is calculated as

$$
\begin{gathered}
\tau_{\max , 1,2}=\frac{\sigma_{1}-\sigma_{2}}{2}, \\
\tau_{\max , 1,3}=\frac{\sigma_{1}-\sigma_{3}}{2}, \\
\tau_{\max , 2,3}=\frac{\sigma_{2}-\sigma_{3}}{2} .
\end{gathered}
$$

The von Mises stress in (5) can be written in terms of principal stress as

$$
\sigma_{v}=\sqrt{\frac{\left(\sigma_{1}-\sigma_{2}\right)^{2}+\left(\sigma_{2}-\sigma_{3}\right)^{2}+\left(\sigma_{1}-\sigma_{3}\right)^{2}}{2}} .
$$

When $\sigma_{3}=0$, the von Mises stress is

$$
\sigma_{v}=\sqrt{\sigma_{1}^{2}+\sigma_{2}^{2}-\sigma_{1} \sigma_{2}}
$$

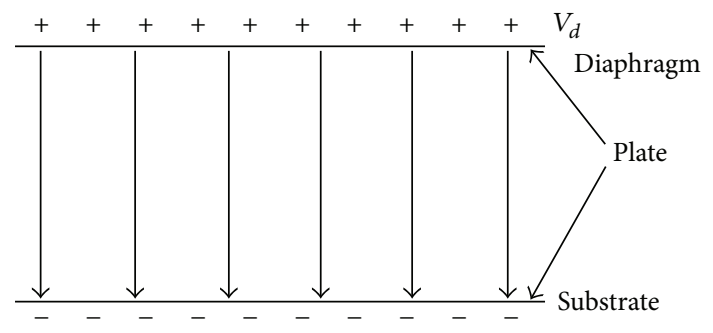

FIGURE 4: The electric field in MEMS pressure sensor.

Note that, when only $\sigma_{x}$ and $\tau_{x y}$ are present, the von Mises stress is

$$
\sigma_{v}=\sqrt{\sigma_{x}^{2}+3 \tau_{x y}^{2}} .
$$

2.2.4. Total Electric Energy Performance. The capacitance describes the space between two electrodes which will be affected by an electric field. If two metal plates are placed with a gap between them and a voltage is applied to one of the plates, an electric field will exist between the plates. The electric field will experience a force from pressure when it is in a region where an electric field exists. From the definition of the electric field, this force is given by [11]

$$
\vec{F}=q \vec{E},
$$

where $\vec{F}$, the force, is exerted on the electrode diaphragm, $q$ is the charge of the particle between electrodes, and $\vec{E}$ is the electric field. When an electron $(q=-e)$ is in an electric field, the electron experiences a force in the direction opposite to the electric field by applying a potential difference $V_{\text {acc }}$ between two electrodes. $m$ is the mass of the electron. Electrons entering the deflection plates have a velocity $v_{x}$ given by (9)

$$
v_{x}=\sqrt{\frac{2 e V_{\mathrm{acc}}}{m}} .
$$

After electrons leave to another electrode, the electric field in between the plates is approximately uniform by applied voltage, $V_{d}=1$ Volt, across the plates, as depicted in Figure 4 [12].

A measure of the deflecting electric field is given by

$$
E_{y}^{\text {deflect }}=-\frac{d V}{d y}=-\frac{V_{d}}{d} .
$$

The average field by replacing the derivative with the voltage difference is divided by $d$, the distance between the plates. However, for large deflection, diaphragm plates are applied by different uniform pressure; thus the average field and the local field are quite close in value. The electric field which will exert a force on the electron with opposite direction of the arrow in Figure 4 can cause the trajectory of the electron to be altered, as depicted in Figure 5. A negatively charged electron is deflected in an electric field. It is repelled 


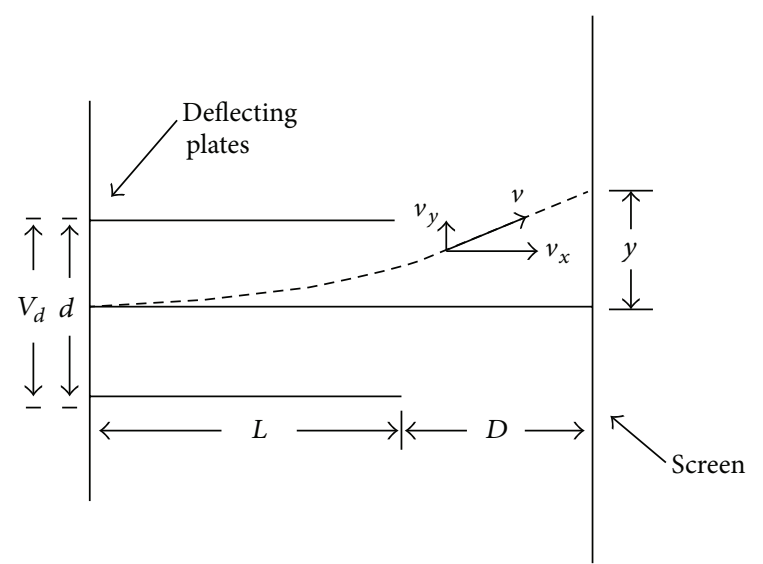

FIGURE 5: Effect deflection plates with electrical energy.

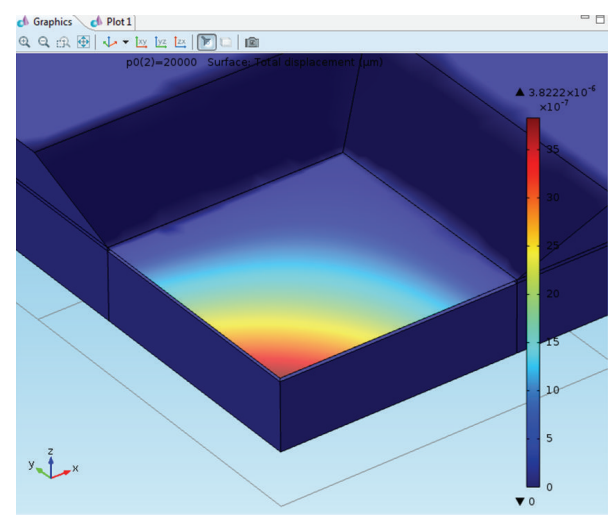

FIGURE 6: Structure surface deflection of diaphragm with applied pressure.

from the negative plate and attracted towards the positive plate [13].

Using Newton's second law and the kinematic equations, the distance in which the electron is deflected, $y$, is given by [14]

$$
y=\frac{e E_{y}^{\text {deflect }} L}{m v_{x}^{2}}\left(D+\frac{L}{2}\right),
$$

where $L$ is the length of the plates, $d$ is their separation, and $D$ is the distance from the end of the plates to the viewing screen.

\section{Results and Discussions}

3.1. Deflection versus Pressure of the Diaphragm. Initially, the COMSOL 4.3 simulation is simplified and performed on MEMS capacitive pressure sensor diaphragm as depicted in Figures 6 and 7. Figure 8 represents the centre deflection of the diaphragm as a function of the external pressure. It is observed that the deflection is distributed throughout the center of the diaphragm due to applied pressure on its surface. Approximately, the pressure applied on diaphragm

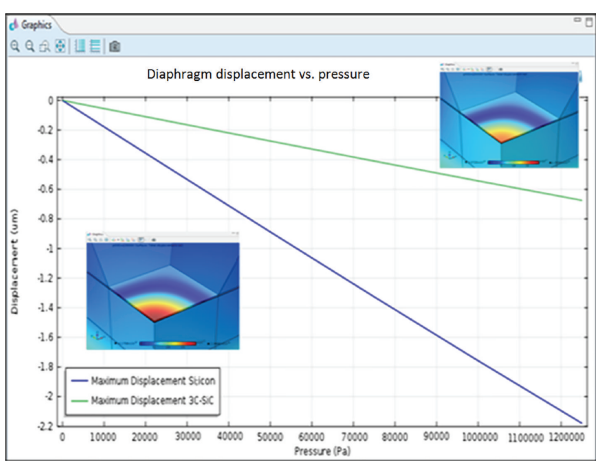

Figure 7: Plot of deflection of the diaphragm versus pressure.

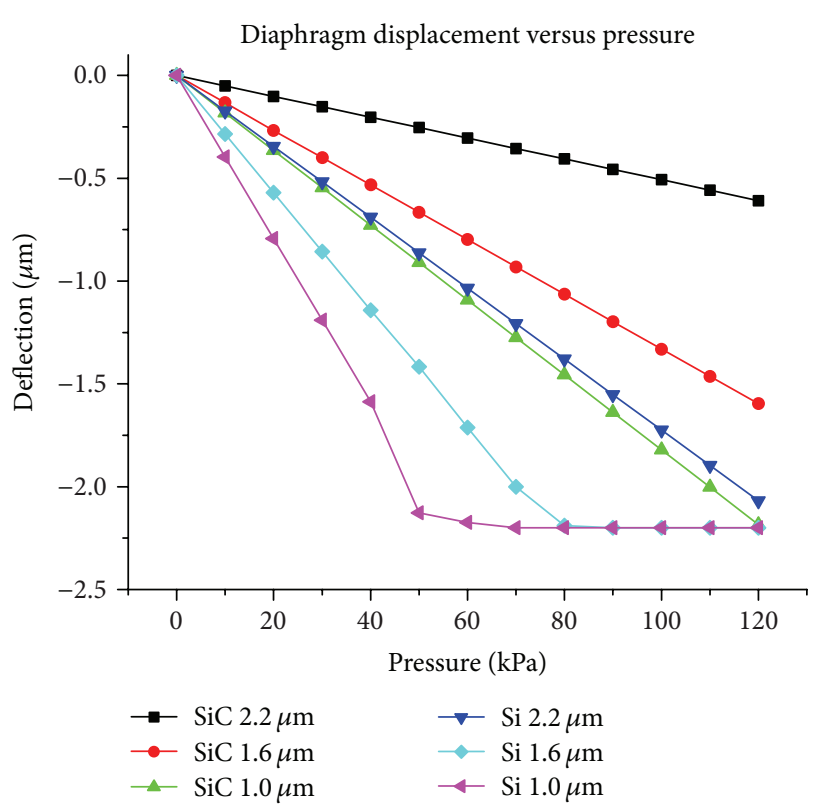

Figure 8: Comparison of deflection versus pressure for 3C-SiC and Si with differential thicknesses of diaphragm.

surface is between $0 \mathrm{kPa}$ and $120 \mathrm{kPa}$. The verification of $3 \mathrm{C}-\mathrm{SiC}$ result for pressure-deflection was obtained the small deflection increases linearly that two surfaces were not touching to the substrate. The thicknesses of $1.0 \mu \mathrm{m}, 1.6 \mu \mathrm{m}$ and $2.0 \mu \mathrm{m}$ is deflect at $0.609 \mu \mathrm{m}, 1.596 \mu \mathrm{m}$ and $2.184 \mu \mathrm{m}$, respectively. Compared to $\mathrm{Si}$, the diaphragm thickness of $1.0 \mu \mathrm{m}$ and $1.6 \mu \mathrm{m}$ starts to touch the substrate at the pressure of $80 \mathrm{kPa}$ and $50 \mathrm{kPa}$, respectively, due to the mechanical properties such that Young's modulus and Poisson's ratio of Si cannot withstand the higher pressure when referring to (1). The performance diaphragm thickness of a $2.2 \mu \mathrm{m}$ of $\mathrm{Si}$ demonstrated that the deflection was increased linearly and not in contact with substrate.

Therefore, we concluded that the simulation results presented in Figure 8 indicated that the thickness of the diaphragm is strongly affected by the deflection of MEMS pressure sensor. A thin diaphragm is more sensitive than a thick diaphragm. It can be seen that the diaphragm deflection increases with the increase of applied pressure. Comparing 


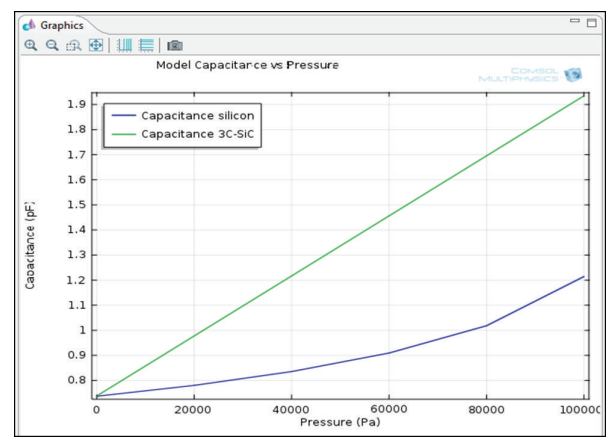

FIGURE 9: Plot of capacitance of the diaphragm versus pressure.

the simulation results between $3 \mathrm{C}-\mathrm{SiC}$ and $\mathrm{Si}$ with different thicknesses, the pressure-deflection was observed such that the $3 \mathrm{C}-\mathrm{SiC}$ is capable of withstanding higher applied pressures up to $120 \mathrm{kPa}$. Replacing 3C-SiC in MEMS applications exhibits excellent mechanical and electrical properties compared to Si materials.

\subsection{Capacitance versus Pressure and Operating Temperature.} Figure 9 shows the plots of capacitance with operating temperatures of both 3C-SiC and Si. In MEMS pressure sensor, the diaphragm capacitance is measured by applying pressure on diaphragm's surface. In our case, the working pressure was applied on the diaphragm between $0 \mathrm{kPa}$ and $100 \mathrm{kPa}$. From Figure 10, it could be seen that the capacitance increases linearly for $3 \mathrm{C}-\mathrm{SiC}$ with the pressure up to $100 \mathrm{kPa}$, while Si materials inherently nonlinear characteristic have been demonstrated due to shear stress and strain distribution on the diaphragm caused by external high pressure [15]. The diaphragm based 3C-SiC materials for the thicknesses of $1.0 \mu \mathrm{m}, 1.6 \mu \mathrm{m}$, and $2.2 \mu \mathrm{m}$ was evaluated with higher capacitance value with comparative performance of good linearity, large operating pressure range of $0 \mathrm{kPa}$ to $100 \mathrm{kPa}$ with the maximum capacitance of $1.34 \mathrm{pF}, 1.65 \mathrm{pF}$, and $1.93 \mathrm{pF}$, respectively. In contrast, $\mathrm{Si}$ materials were performed nonlinearly with lower capacitance value of $0.90 \mathrm{pF}, 1.10 \mathrm{pF}$, and $1.22 \mathrm{pF}$, respectively. It is demonstrated that $3 \mathrm{C}-\mathrm{SiC}$ has excellent materials with incredibly high pressure. Nonlinear response of a capacitance-pressure is due to the $\mathrm{Si}$ materials could not enduring at high pressures in predicting the damage or fracture of the diaphragm [16].

Figure 11 shows the effects of 3D modeling MEMS capacitive pressure sensor of $3 \mathrm{C}-\mathrm{SiC}$ with pressure applied of $120 \mathrm{kPa}$ and temperatures of $1000 \mathrm{~K}$. The simulation of capacitance versus operating temperature for $3 \mathrm{C}-\mathrm{SiC}$ and Si from COMSOL ver. 4.3 software is plotted in Figure 12. In Figure 13 the comparison of capacitance versus pressure for $3 \mathrm{C}-\mathrm{SiC}$ and $\mathrm{Si}$ materials with varying thicknesses of the diaphragm with applied pressure between $0 \mathrm{kPa}$ and $120 \mathrm{kPa}$ with temperatures from $290 \mathrm{~K}$ to $1000 \mathrm{~K}$ could be seen. For $3 \mathrm{C}-\mathrm{SiC}$, the simulation result shows that the capacitance performance decreases linearly with increasing operating temperature. Compared to $\mathrm{Si}$ materials, it was found that capacitance-operating temperature response is non-linear. It is revealed that non-linear at the temperature

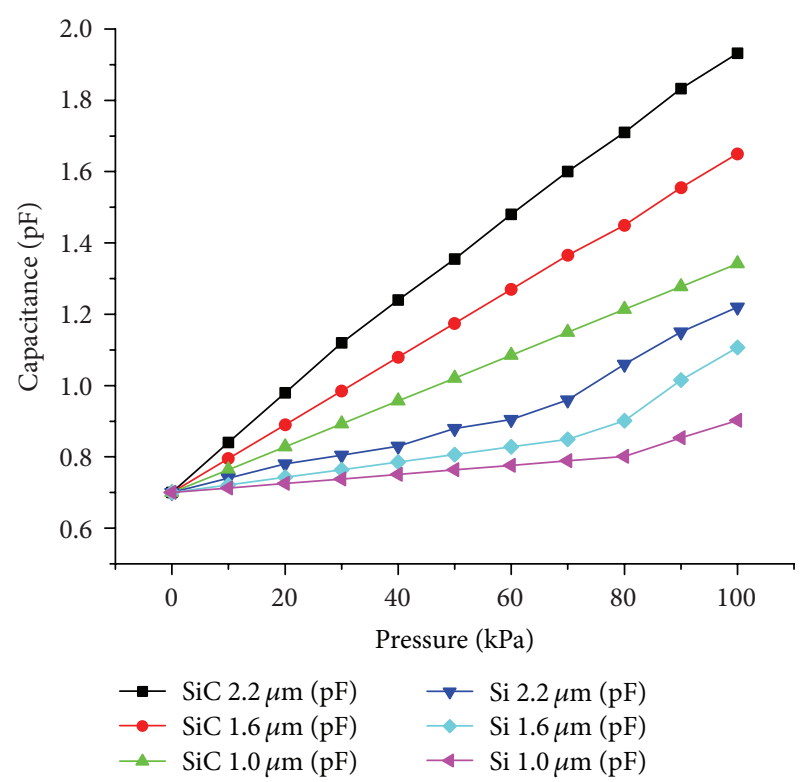

FIGURE 10: Comparison of capacitance versus pressure for 3C-SiC and $\mathrm{Si}$ with differential thicknesses of diaphragm.

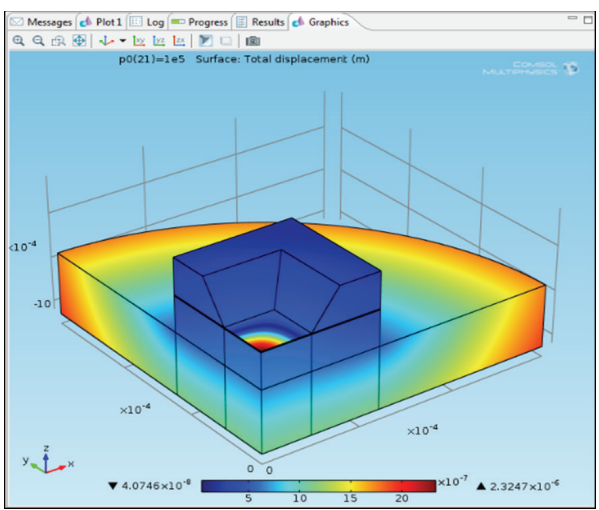

FIGURE 11: Structure surface of diaphragm with maximum applied pressure and temperature.

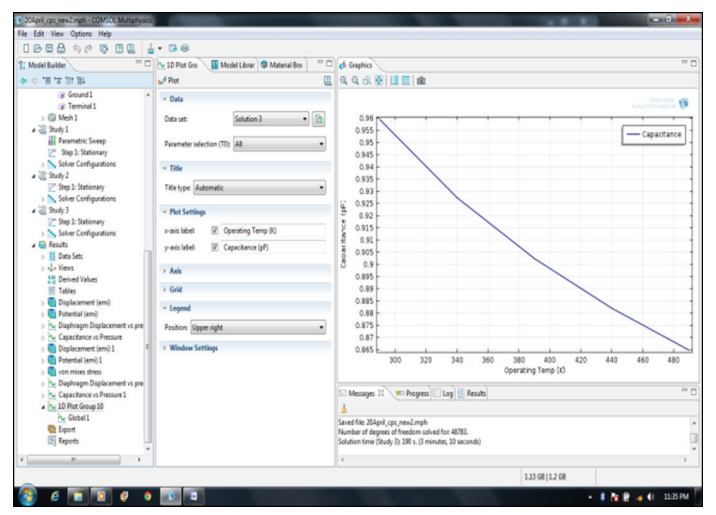

FIGURE 12: Plot of capacitance versus operating temperature in MEMS capacitive pressure sensor. 


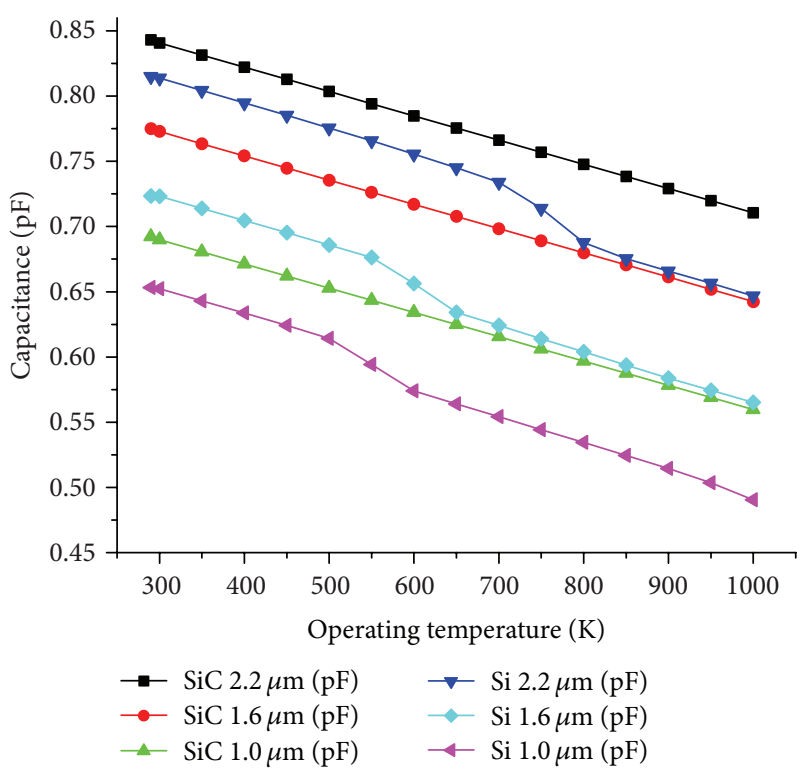

FIGURE 13: Comparison of capacitance versus operating temperature of $3 \mathrm{C}-\mathrm{SiC}$ and $\mathrm{Si}$ with differential thickness of diaphragm.

extremes indicate the stress distribution on the diaphragm. The diaphragm based $3 \mathrm{C}-\mathrm{SiC}$ materials exhibits large changes in capacitance at high temperature of $1000 \mathrm{~K}$ with varying thicknesses of $1.0 \mu \mathrm{m}, 1.6 \mu \mathrm{m}$, and $2.2 \mu \mathrm{m}$ with the capacitance value of $0.56 \mathrm{pF}, 0.64 \mathrm{pF}$, and $0.71 \mathrm{pF}$, respectively. Si has lower capacitance value with maximum capacitance of $0.49 \mathrm{pF}$, $0.57 \mathrm{pF}$, and $0.65 \mathrm{pF}$ due to its relatively superior thermal and electrical properties.

It is evident that $3 \mathrm{C}-\mathrm{SiC}$ is capable of functioning for extreme temperature; high power conditions enable producing high performance enhancement to a wide variety of systems and applications [17]. In contrast, Si materials show that the capacitance decrease nonlinearity with operating temperature due to the limitation of mechanical and electrical properties does not endure extreme temperature. This is because of the dielectric losses caused by change in the field of mechanical properties such as elastic modulus which decreases with increasing temperature [18]. The simulation results revealed that $\mathrm{Si}$ is not suitable materials to be applied for extreme temperature applications.

3.3. Maximum von Mises Stress versus Pressures and Operating Temperatures. Figure 14 illustrated the maximum von Mises stress distribution on the MEMS capacitive pressure sensor diaphragm as the applied pressure and temperature due to the effect of friction heat and elastic deformation on the surface of the diaphragm. It can be found that as the pressure and operating temperature increase, the maximum von Mises stress linearly increases for $3 \mathrm{C}$ - $\mathrm{SiC}$, while nonlinearity increases for Si materials shown in Figure 15. The main reason can be that von Mises stress distribution on the diaphragm increases linearity which has proven that $3 \mathrm{C}-\mathrm{SiC}$ materials can generate some amount of thermal energy.

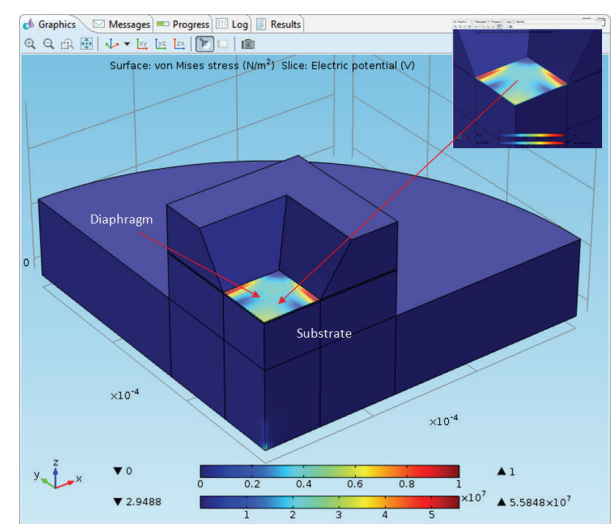

FIGURE 14: Structure surface of diaphragm with maximum von Mises stress with applied pressure.

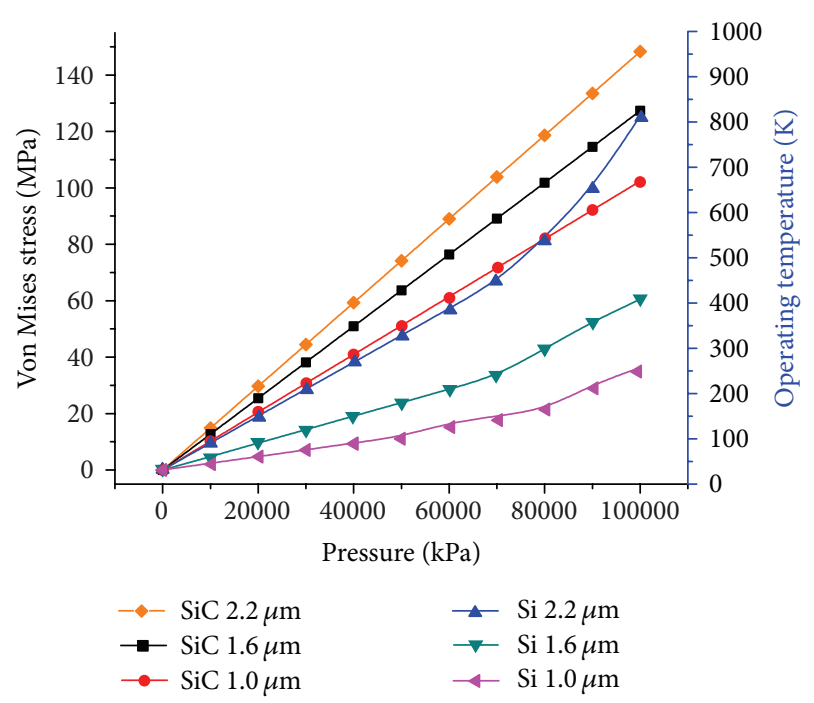

FIGURE 15: Comparison of von Mises stress versus differential pressure and temperature for $3 \mathrm{C}-\mathrm{SiC}$ and $\mathrm{Si}$ with differential thickness of diaphragm.

The results also show the effect of strain and stress which appear on the surface of diaphragm at the point of loading pressure. For 3C-SiC, the maximum von Mises stress with an applied pressure of $100 \mathrm{kPa}$ and temperature of $1000 \mathrm{~K}$ increases linearly with the thickness of the diaphragm which is $1.0 \mu \mathrm{m}, 1.6 \mu \mathrm{m}$, and $2.2 \mu \mathrm{m}$ with higher value of von Mises stress which is 102.38 MPa, 127.31 MPa, and 148.32 MPa compared to $\mathrm{Si}$ which is $36.36 \mathrm{MPa}, 60.51 \mathrm{MPa}$, and $125.48 \mathrm{MPa}$, respectively. It is demonstrated that the linear analysis indicates a uniform state of stress proportional to the strain as referred to (5) function as well as high sensitivity for a MEMS capacitive pressure sensor equipped with thickness of the diaphragm [19]. It is revealed that 3C-SiC material can survive for resisting a very high pressure and extremely high temperatures without fracture.

For Si materials, the results present more realistic nonlinear responses to an applied pressure and operating temperature explained the unconditional stability of the materials 
with respect to strain increments. It is possible that the high stresses monitored at these stress concentration areas are due to thermal stresses caused by thermal expansion and contraction of the materials produced by thermal gradient [20]. The major thermal stress induced can cause failure of diaphragm materials that affects the nonlinear behavior exhibited under prestressing and thermal effects.

3.4. Total Electric Energy Performance with Applied Pressure. Figure 16 highlights that total electric energy possesses applied pressure despite having similar layout size, with the only difference thickness of the diaphragm simulated in COMSOL 4.2 software. The expression of total electric energy is defined by (8) for the center deflections due to electrical biasing field between two electrodes responses to pressure applied on the surface of diaphragm with the input voltage remaining 1.0 Volt.

In Figure 17, the effects of comparing total electrical energy at varying pressures for both materials $3 \mathrm{C}-\mathrm{SiC}$ and $\mathrm{Si}$ could be seen. It is observed that total electrical energy for Si significantly increases with increasing applied pressure for the diaphragm thickness of $1.0 \mu \mathrm{m}, 1.6 \mu \mathrm{m}$, and $2.2 \mu \mathrm{m}$ is 1.81 $\times 10^{-12} \mathrm{~J}, 2.09 \times 10^{-12} \mathrm{~J}$, and $2.53 \times 10^{-12} \mathrm{~J}$, respectively. Similar trend is observed for $3 \mathrm{C}-\mathrm{SiC}$, but the rate of total electric energy significantly lowers for the diaphragm thickness of $1.0 \mu \mathrm{m}, 1.6 \mu \mathrm{m}$, and $2.2 \mu \mathrm{m}$ is $4.34 \times 10^{-13}, 4.68 \times 10^{-13}$, and $5.57 \times 10^{-13}$, respectively. This is due to the fact that charge of the particle between diaphragm and substrate interface was affected by an electrode material's energy between electrodes.

The novelty of the study was the use of 3C-SiC materials that can minimized the total electric energy with applied pressure. A distributed applied pressure loading, the applied physical strain, and deformation can be subject to changes in electrical energy performance. Typically, electric energy was acutely affected by the thickness of the top electrode; in this case, the diaphragm has a significant impact on electric energy because of its ability to change resulting from an applied pressure which also exhibits long-term electric energy saving relatively cheap [21].

For the purpose of studying effects of the design thickness changes, it can be concluded that the maximum applied pressure of $100 \mathrm{kPa}$ shows the lowest electric energy with electric energy less than $5.87 \times 10^{-13} \mathrm{~J}$ of $3 \mathrm{C}$-SiC compared with $\mathrm{Si}$ of $2.53 \times 10^{-12} \mathrm{~J}$, thus having more than $50 \%$ saving as compared to Si.

\section{Conclusion}

The simulation results through interactive $3 \mathrm{D}$ plots of COMSOL ver. 4.3, 3C-SiC, improved the capacitance performance increase linearly with maximum capacitance of $1.93 \mathrm{pF}$ compared to $\mathrm{Si}$ increasing nonlinearly with maximum capacitance of $1.22 \mathrm{pF}$. This is due to the fact that $3 \mathrm{C}-\mathrm{SiC}$ thin film maintains its structural integrity of high Young's modulus and thermal conductivity that can withstand operating at extreme temperature. In terms of the maximum von Mises stress induced on the centre of the diaphragm, the 3C-SiC thin film performed increases linearly with high von Mises

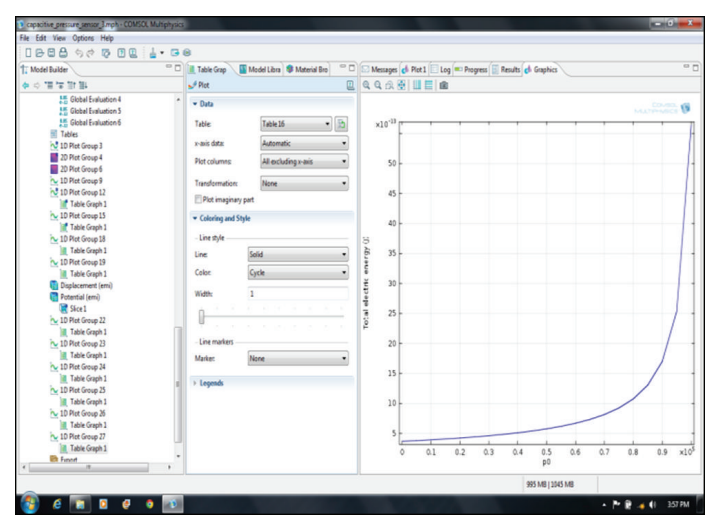

FIGURE 16: Plot of total electric energy versus pressure in MEMS capacitive pressure sensor.

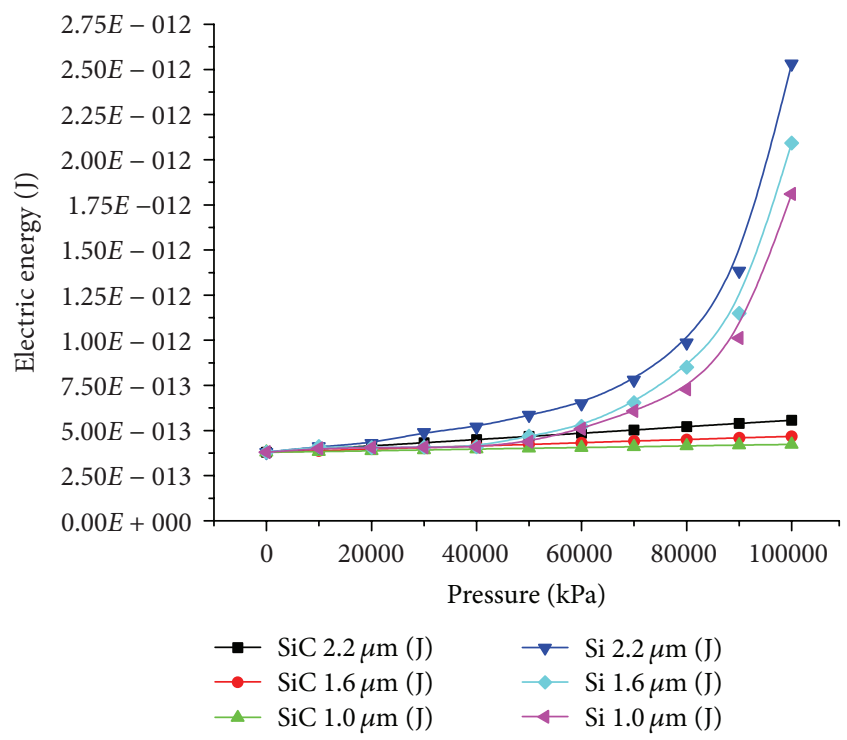

FIGURE 17: Comparison of total electric energy versus pressure for $3 \mathrm{C}-\mathrm{SiC}$ and $\mathrm{Si}$ with differential thickness of diaphragm.

stress which is $148.32 \mathrm{MPa}$ at $1000 \mathrm{~K}$, while $\mathrm{Si}$ thin film is 125.38 MPa only. In terms of electrical performance for 3C$\mathrm{SiC}$ based sensor, the maximum output capacitance of $1.93 \mathrm{pF}$ is achieved with less total electrical energy of $5.87 \times 10^{-13} \mathrm{~J}$, thus having a more than $50 \%$ saving as compared to $\mathrm{Si}$. These results highlight the superiority of $3 \mathrm{C}$ - $\mathrm{SiC}$ compared to $\mathrm{Si}$ in terms of mechanical and electrical performance, thus making it favorable for MEMS capacitive pressure sensor. It has been proven to be the most suitable material applied for extremely high temperatures and high pressures.

\section{Conflict of Interests}

The authors declare that there is no conflict of interests regarding the publication of this paper. 


\section{Acknowledgments}

The authors would like to thank the Institute Microengineering and Nanoelectronic (IMEN) of Universiti Kebangsaan Malaysia (UKM), Science-fund MOSTI for supporting this project under Grant 03-01-02-SF0849, and Queensland Micro- and Nanotechnology Centre (QMNC) of Griffith University for providing the resources and facilities in part at the Queensland node of the Australian National Fabrication Facility, a company established under the National Collaborative Research Infrastructure Strategy to provide nano- and microfabrication facilities for Australia's researchers.

\section{References}

[1] Q. Zhao and X. Xiong, "MEMS pressure sensor for high-temperature application," in Proceedings of the American Society for Engineering Education Northeast Section Conference (ASEE '10), Boston, Mass, USA, 2010.

[2] R. G. Azevedo, J. Zhang, D. G. Jones et al., "Silicon carbide coated mems strain sensor for harsh environment applications," in Proceedings of the 20th IEEE International Conference on Micro Electro Mechanical Systems (MEMS '07), pp. 643-646, January 2007.

[3] M. Mehregany, C. A. Zorman, N. Rajan, and C. H. Wu, "Silicon carbide MEMS for harsh environments," Proceedings of the IEEE, vol. 86, no. 8, pp. 1594-1609, 1998.

[4] M. B. J. Wijesundara and R. G. Azevedo, Silicon Carbide Microsystems for Harsh Environments, vol. 22 of MEMS Reference Shelf, Springer, 2011.

[5] N. Marsi, B. Y. Majlis, A. A. Hamzah, and F. Mohd-Yasin, "Comparison of mechanical deflection and maximum stress of 3C$\mathrm{SiC}$ and Si-based pressure sensor diaphragms for extreme environment," in Proceedings of the Semiconductor Electronics (ICSE '12), pp. 186-190, 2012.

[6] J. Du, D. J. Young, C. A. Zorman, and W. H. Ko, "Single crystal $\mathrm{SiC}$ capacitive pressure sensor at $400^{\circ} \mathrm{C}$," in Proceedings of the IEEE International Electron Devices Meeting (IEDM '03), pp. 783-786, December 2003.

[7] R. Khakpour, S. R. M. Mansouri, and A. R. Bahadorimehr, "Analytical comparison for square, rectangular and circular diaphragms in MEMS applications," in Proceedings of the International Conference on Electronic Devices, Systems and Applications (ICEDSA '10), pp. 297-299, April 2010.

[8] M. Damghanian, Design and Fabrication of a MEMS Tactile Pressure Sensor Array for Fingerprint Imaging, Universiti Kebangsaan Malaysia, Bangi, Malaysia, 2009.

[9] P. M. Kurowski, Engineering Analysis With Solidworks Simulation, Schroff Development Corporation, 2012.

[10] H. Tai-Ran, MEMS and Microsystems: Design, Manufacture and Nanoscale Engineering, John Wiley \& Sons, New York, NY, USA, 2008.

[11] A. C. Zonnevylle, T. Verduin, C. W. Hagen, and P. Kruit, "Deflection properties of an electrostatic electron lens with a shifted electrode," Journal of Vacuum Science and Technology B, vol. 31, no. 6, pp. 06F702-06F702-7, 2013.

[12] H. Xiao, Dynamic defocusing in streak tubes [thesis of laboratory for laser energetic], University of Rochester, 2012.

[13] Z. Zhang, L. Li, X. Xie, D. Xiao, and W. He, "Optimization design and research character of the passive electric field sensor," IEEE Sensors Journal, vol. 14, no. 2, pp. 508-513, 2014.
[14] M. V. Kuzelev, G. P. Mkheidze, A. A. Rukhadze, P. S. Strelkov, and A. G. Shkvarunets, Electron Beam Generated Plasmas: Theory, Experiments, Applications, vol. 67 of Advanced Technologies Based on Wave and Beam Generated Plasmas NATO ASI Series, 1999.

[15] H.-Y. Ma, Q.-A. Huang, M. Qin, and T. Lu, "A micromachined silicon capacitive temperature sensor for radiosonde applications," in Proceedings of the IEEE Sensors Conference (SENSORS '09), pp. 1693-1696, October 2009.

[16] A. E. Medler, A thin monocrystalline diaphragm pressure sensor using silicon-on-insulator technology [thesis degree of doctor of philosophy, School of Engineering Systems], Middlesex University, 1998.

[17] N. Marsi, B. Y. Majlis, F. Mohd-Yasin, and A. A. Hamzah, "The capacitance and temperature effects of the $\mathrm{SiC}$ - and $\mathrm{Si}$ - based mems pressure sensor," Journal of Physics: Conference Series, vol. 431, pp. 1-9, 2013.

[18] J. Gomes and H. R. Shea, "Displacement damage effects in silicon MEMS at high proton doses," in Reliability, Packaging, Testing, and Characterization of MEMS/MOEMS and Nanodevices X, vol. 7928 of Proceedings of SPIE, January 2011.

[19] A. Benmeddour, S. Meziani, and Numerical study of thermal stress during different stages of silicon Czochralski crystal growth, Revue des Energies Renouvelables, vol. 12, pp. 575-584, 2009.

[20] M. Zang, D. L. Polla, S. M. Zurn, and T. Cui, "Stress and deformation of pzt thin film on silicon wafer due to thermal expansion," in Symposia BB-Multicomponent Oxide Films for Electronics, vol. 574 of MRS Proceedings, 1999.

[21] Y. Hezarjaribi, M. N. Hamidon, S. H. Keshmiri, and A. R. Bahadorimehr, "Capacitive pressure sensors based on MEMS, operating in harsh environments," in Proceedings of the IEEE International Conference on Semiconductor Electronics (ICSE '08), pp. 184-187, November 2008. 

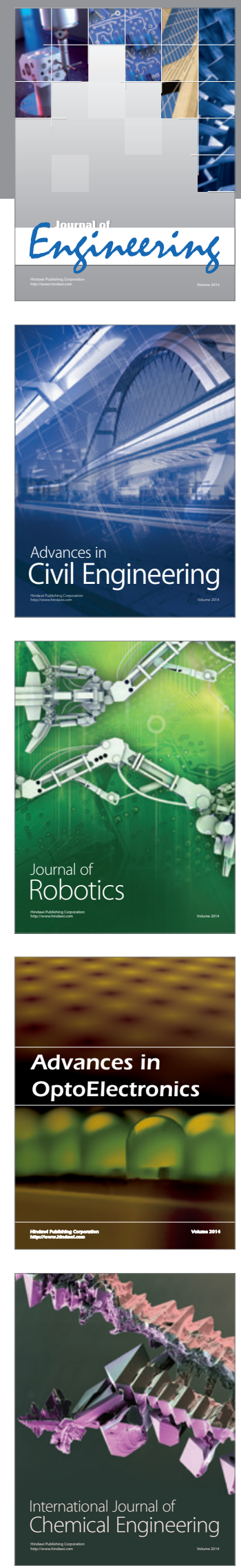

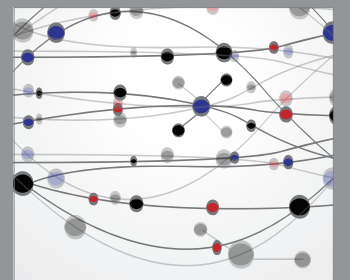

The Scientific World Journal
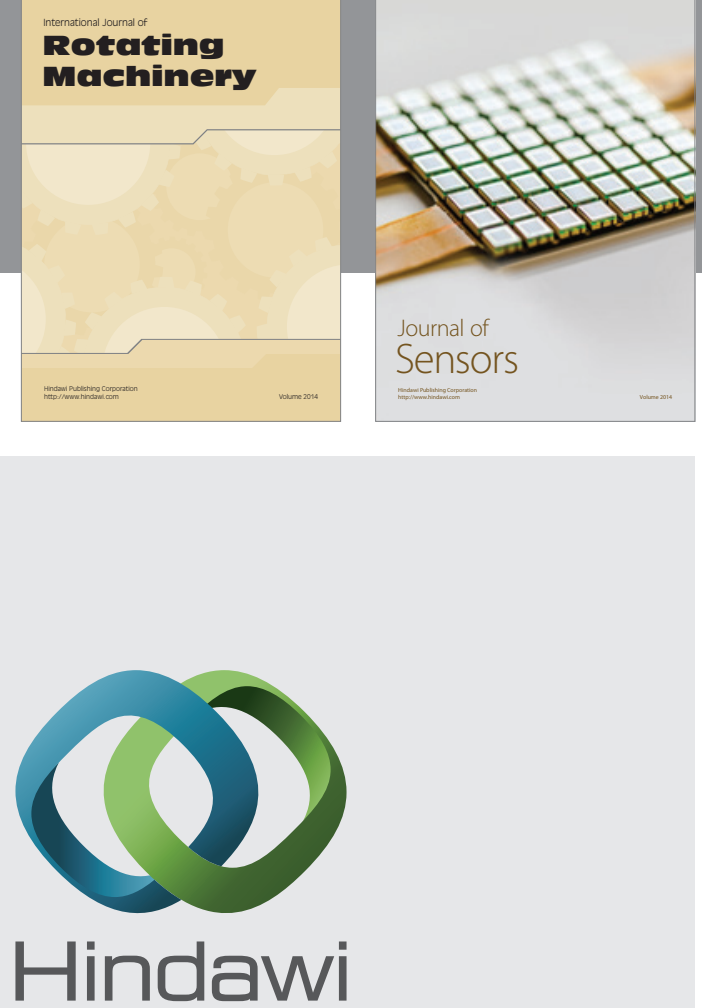

Submit your manuscripts at http://www.hindawi.com
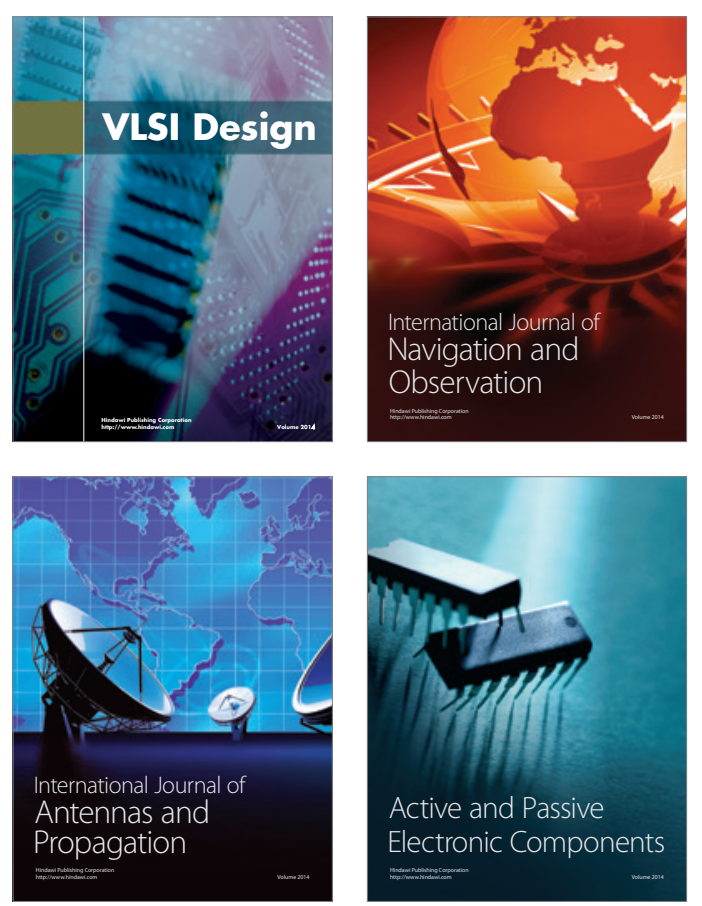
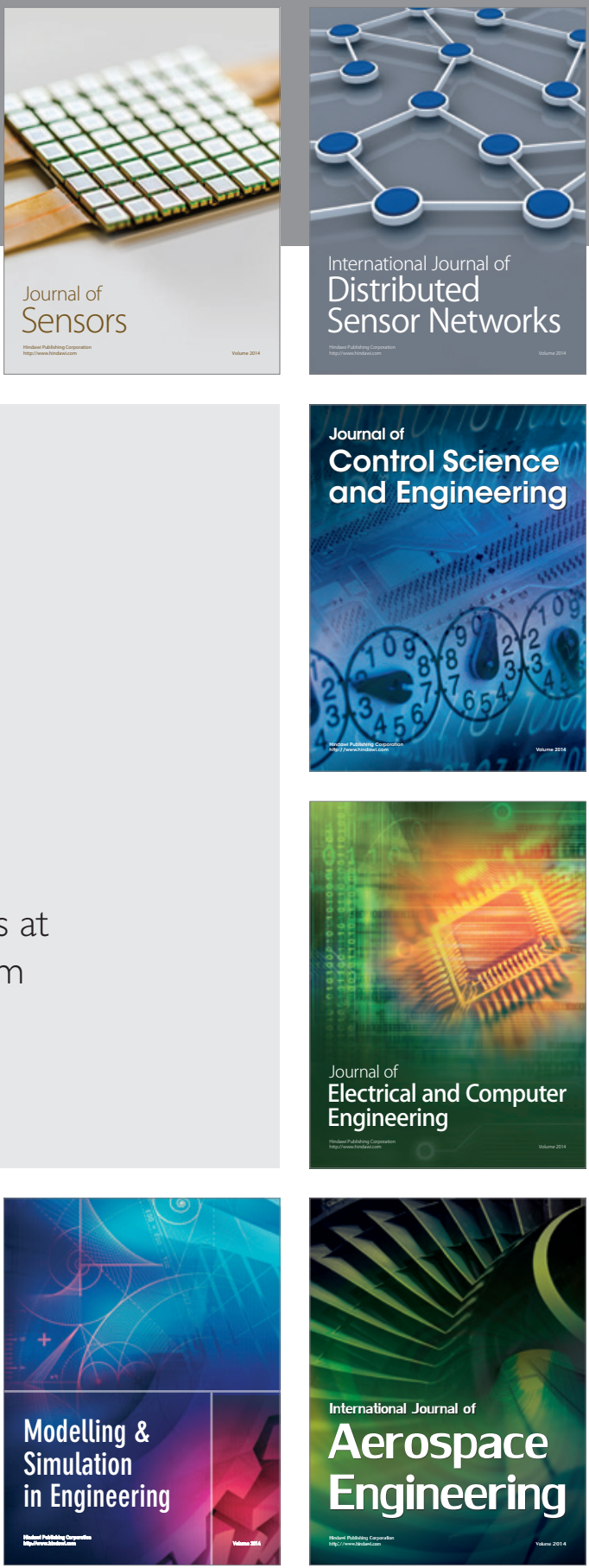

Journal of

Control Science

and Engineering
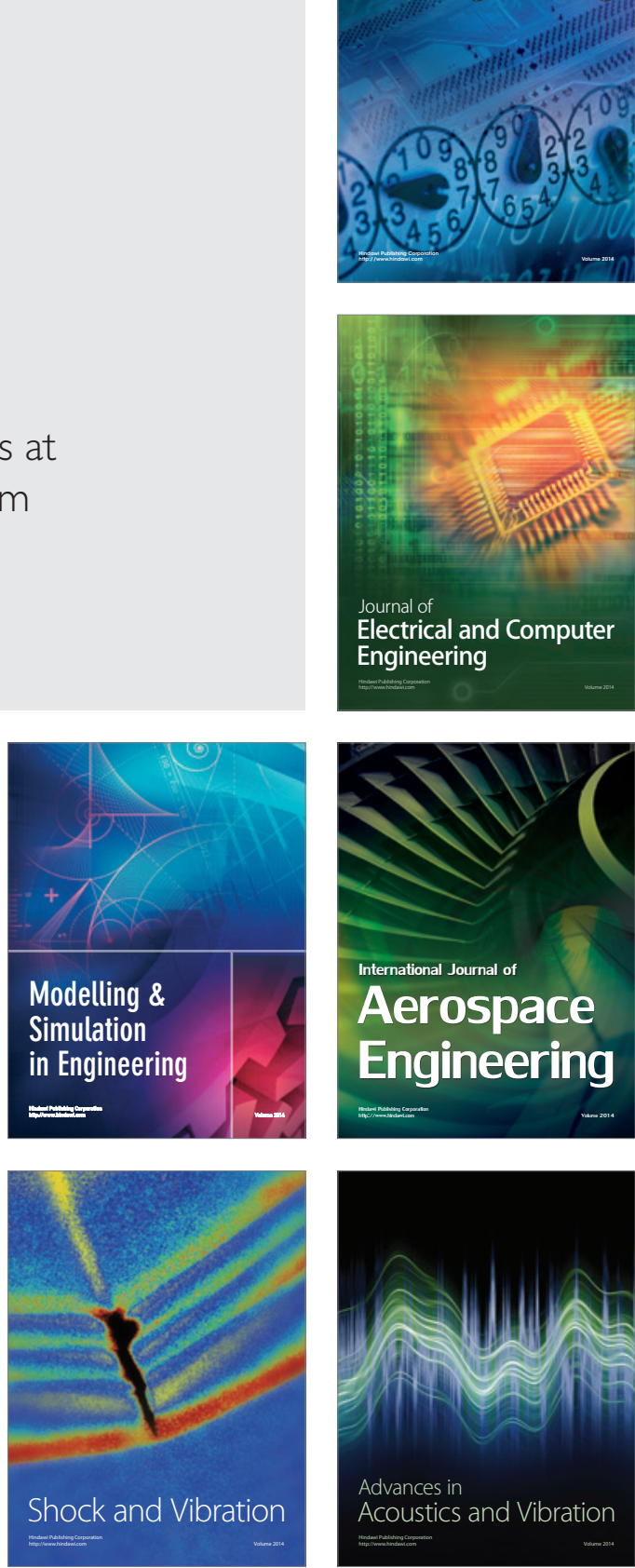